\title{
UPAYA PENINGKATAN SISTEM MANAJEMEN MUTU DALAM PENERAPAN (ISO 9001, 2015) DI PT. DINAR MAKMUR
}

\author{
Afif Hakim ${ }^{1}$, Ni Wayan Puji $\mathrm{E}^{2}$ \\ ${ }^{1}$ Jurusan Teknik Industri, Fakultas Teknik dan Ilmu Komputer, Universitas Buana Perjuangan Karawang \\ Jl. HS. Ronggowaluyo Telukjambe Timur Karawang, \\ ${ }^{2}$ Jurusan Teknik Informatika, Fakultas Teknik dan Ilmu Komputer, Universitas Buana Perjuangan Karawang \\ Jl. HS. Ronggowaluyo Telukjambe Timur Karawang \\ Email: afif.hakim@ubpkarawang.ac.id
}

\begin{abstract}
The problem with the company is the increase in non-conformance findings in the internal ISO audit report which is very significant, namely as many as 20 findings related to clause 7.2 of controlling information documents within a period of 6 months. Therefore, the main problem raised in this analysis is how to reduce the findings of non-conformities in the results of internal audit and document management at PT. Dinar Makmur uses fishbone diagrams, PLAN-DO-CHECK-ACTION (PDCA) cycles and provides training for employees to employee evaluations until the findings of the company's internal audit results decline. After that, a calculation of the improvements that have been made is carried out by adding up the clause findings obtained after the audit and divided by the number of sections/departments multiplied by the number of points audited. So the results of the increase in the value of the audit as much as $12 \%$ success rate from before the repair. After improvements were made, there was a decrease in findings in the previous period January-June 2018 as many as 40 findings and in the July-December 2018 period as many as 30 findings, and the difference in the decline that has been achieved is 10 findings.
\end{abstract}

Keyword: fishbone diagram; PDCA; audit ISO

\begin{abstract}
ABSTRAK
Masalah yang terdapat pada perusahaan adalah kenaikan temuan ketidaksesuaian pada laporan audit ISO internal yang sangat signifikan yaitu sebanyak 20 temuan terkait klausul 7.2 pengendalian dokumen informasi dalam kurun waktu 6 bulan. Oleh karena itu, permasalah utama yang diangkat pada analisis ini yaitu bagaimana cara untuk menurunkan temuan ketidaksesuaian pada hasil audit internal dan manajemen dokumen di PT. Dinar Makmur dengan menggunakan fishbone diagram, siklus PLAN - DO - CHECK - ACTION (PDCA) serta memberikan pelatihan terhadap karyawan sampai evaluasi karyawan hingga temuan hasil audit internal perusahaan menurun. Setelah itu, dilakukan penghitungan perbaikan yang sudah dilakukan dengan menjumlahkan temuan klausul yang didapatkan setelah dilakukannya audit dan dibagi dari jumlah bagian/departemen dikalikan dengan jumlah point yang diaudit. Jadi hasil peningkatan dari nilai audit sebanyak $12 \%$ tingkat keberhasilan dari sebelum dilakukan perbaikan. Setelah dilakukan perbaikan terlihat adanya penurunan temuan di periode sebelumnya Januari-Juni 2018 sebanyak 40 temuan dan pada periode Juli-desember 2018 sebanyak 30 temuan, dan selisih penurunan yang sudah dicapai sebanyak 10 temuan.
\end{abstract}

Kata kunci: fishbone diagram; PDCA; audit ISO

\section{PENDAHULUAN}

Peningkatan persaingan pada pasar global dan harapan konsumen yang tinggi terhadap kualitas produk, mendorong perusahaan untuk menghasilkan produk berkualitas yang memenuhi standar internasional. Salah satu kegiatan dalam meningkatkan kualitas sesuai dengan spesifikasi produk yaitu menerapkan sistem manajemen mutu yang tepat dengan melibatkan semua aspek perusahaan yang terintegrasi pada standar ISO 9001 sebagai panduan. Proses produksi PT Dinar 
Makmur sudah menerapkan sistem manajemen mutu ISO 9001:2008 sejak tahun 2013, dan mengalami pembaharuan sehingga sistem manajemen mutu ISO 9001:2008 kini menjadi sistem manajemen mutu (ISO 9001, 2015) pada tahun 2016.

Sistem manajemen mutu yang diterapkan di PT Dinar Makmur telah berjalan, tetapi penerapan dan tingkat konsistensi pada karyawan khususnya dibagian lapangan masih belum sesuai karena terlihat pada laporan hasil audit internal di perusahaan yang berjalan sangat signifikan sekali menaik pada klausul 7.2 pengendalian dokumen informasi, seharusnya pada sistem manajemen mutu (ISO 9001, 2015) yaitu bagaimana cara agar karyawan mempermudah hasil pekerjaan dan cara untuk memperbaiki hasilnya. Maka untuk mengoptimalkan pengendalian dokumen yang ada di dalam perusahaan dan agar menurunkan hasil audit internal perlu dilakukan improvement terhadap pengendalian dokumen informasi dalam penerapan manajemen mutu (ISO 9001, 2015) studi kasus di PT Dinar Makmur.

Pada Audit Internal yang dilakukan oleh PT. Dinar Makmur yang dilaksanakan setiap 6 bulan sekali, terjadinya temuan audit yang sangat signifikan meningkat pada periode Jan-Jul 2018 ke JulDes 2018 yaitu sebesar 20 temuan dengan clausul 7.2 Pengendalian dokumen informasi, dapat diketahui bahwa pengendalian dokumen dalam penerapan mamangement mutu (ISO 9001, 2015) di PT. Dinar Makmur harus lebih ditingkatkan kembali untuk memastikan implementasi system pengendalian dokumen berjalan dengan baik dan berkesinambungan. Tujuan dalam upaya meningkatkan sistem manajemen mutu dalam penerapan (ISO 9001, 2015) dan memelihara konsistensi pelaksanaan audit internal di PT. Dinar Makmur ini ada beberapa point diantaranya:

Untuk mengetahui faktor-faktor penyebab apa saja yang mempengaruhi temuan audit internal pada hasil audit internal periode Januari-Juni 2018 sebanyak 20 temuan dan meningkat secara signifikan pada periode Juli-Desember 2018 sebanyak 40 temuan.

Untuk mengetahui perancangan sistem manajemen mutu untuk mempermudah karyawan memahami pekerjaannya sesuai standard sistem mutu (ISO 9001, 2015).

Untuk mengetahui metode yang digunakan menggunakan PDCA (Plan, Do, Check Action) dengan tingkat keberhasilan yang dilakukan dengan menghitung efektifitas dari perbaikan dan perbandingan dua data sebelum dan sesudah dilakukannya perbaikan. Metode Plan Do Check Action atau biasa disebut metode PDCA adalah suatu aktivitas perbaikan berulang untuk mencari solusi dari suatu permasalahan. Metode PDCA digunakan untuk mengetahui dan menentukan akar dari masalah yang sebenarnya, sehingga solusi dari suatu permasalahan tepat dalam penanggulangannya (Kurniawan dan Azwir, 2018).

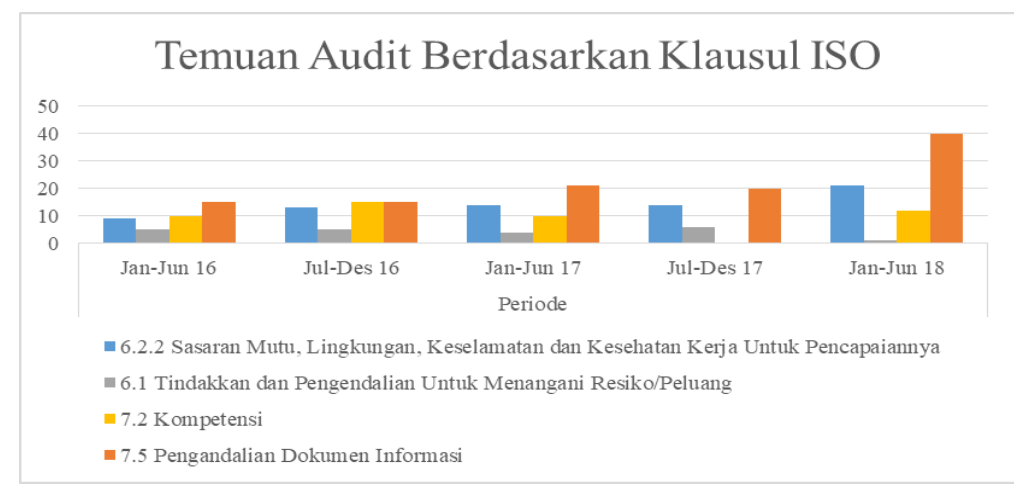

Gambar 1. Grafik temuan audit berdasarkan klausul ISO

ISO (International Organization for Standardization) adalah suatu badan standar dunia yang dibentuk untuk meningktkan perdagangan internasional yang berkaitan dengan barang dan jasa. ISO merupakan organisasi internasional yang bertanggung jawab dalam penyusun standar baru ataupun revisi ISO standar yang telah ada. Standar yang dikeluarkan oleh ISO, dipersiapkan oleh Technical Committee yang mewakili organisasi serta kalangan industri. ISO membawahi sejumlah badan sertifikasi nasional yang terdiri dai 135 negara atau lebih dari seluruh dunia. Pada umumnya, ISO terkait dengan mutu produk maupun jasa dan standar-standar yang telah ditetapkan akan ditinjau kembalidalam kurun waktu 5 tahun untuk memastikan standar tersebut masih relevan dengan 
perkembangan dunia usaha. Standar yang ditetapkan oleh ISO tidak bersifat teknis pelaksanaan tetapi merupakan persyaratan yang harus dipenuhi oleh perusahaan dalam penerapannya (Silaban, 2011).

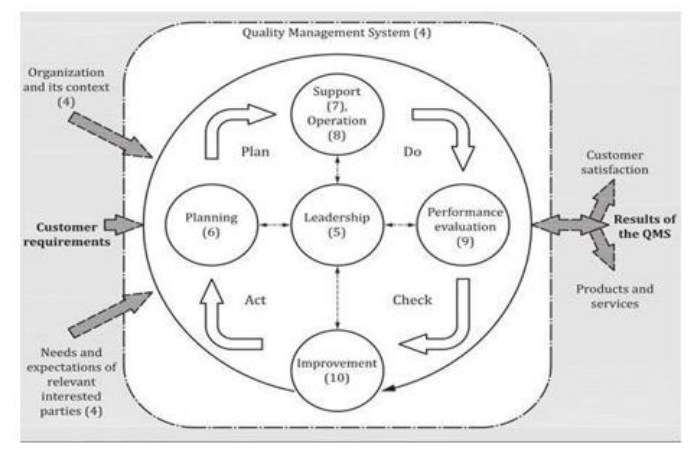

Gambar 2. Model Sistem Manajemen Mutu (ISO 9001, 2015) Sumber : ISO 9001 Quality Management System Requirement, International Organization, Switzerland, 2015

\section{METODE PENELITIAN}

Jenis penelitian pada materi ini adalah kualitatif, dimana pada penelitian ini merupakan salah satu jenis penelitian menggunakan data sebenarnya sesuai dengan fakta yang ada dilapangan sebagai sumber data peristiwa-peristiwa yang terjadi dalam suatu situasi dan data yang diperoleh dari hasil pengamatan, wawancara, hasil pemotretan dan analisis dokumen, catatan lapangan disusun peneliti dilokasi penelitian. Data yang dikumpulkan secara sistematis mengenai fakta objek yang diteliti dengan menggabungkan antara variabel satu dan yang lain. Antara variabel terikat dan bebas tidak mempengaruhi satu sama lain, dan dikaji menurut teori dan literatur-literatur yang telah dipelajari dan berhubungan dengan materi penelitian. Variabel penelitian yang ada pada metode Plan - Do - Check - Action (PDCA) ini berupa data hasil audit internal di PT. Dinar Makmur selama 5 periode, data temuan yang paling banyak timbul saat audit internal, dan data dari Rangkuman Management per 6 bulan sekali.

Prosedur pengambilan data agar penelitian ini dapat terlaksanan adalah sebagai berikut:

Melakukan pengumpulan data dengan studi literatur agar didapatkan referensi untuk kelanjutan penelitian guna mempelajari kasus yang terjadi dalam kaitan tema 'Upaya meningkatkan sistem manajemen mutu dalam penerapan (ISO 9001, 2015) di PT. Dinar Makmur" dengan menggunakan metode Plan - Do - Check - Action pada PT. Dinar Makmur yang berada di devisi quality management Representative.

Studi lapangan, dengan melakukan pengambilan data secara langsung di lokasi PT. Dinar Makmur untuk mengetahui secara langsung masalah yang terjadi.

Mengumpulkan data antara lain:

Data diperoleh dari wawancara operator, supervisor, staff dalam audit internal yang sudah dilakukan didalam perusahaan dengan periode enam bulan sekali

Data hasil laporan audit internal dan tinjauan manajemen serta data bulanan dari laporan sasaran mutu bulanan. 


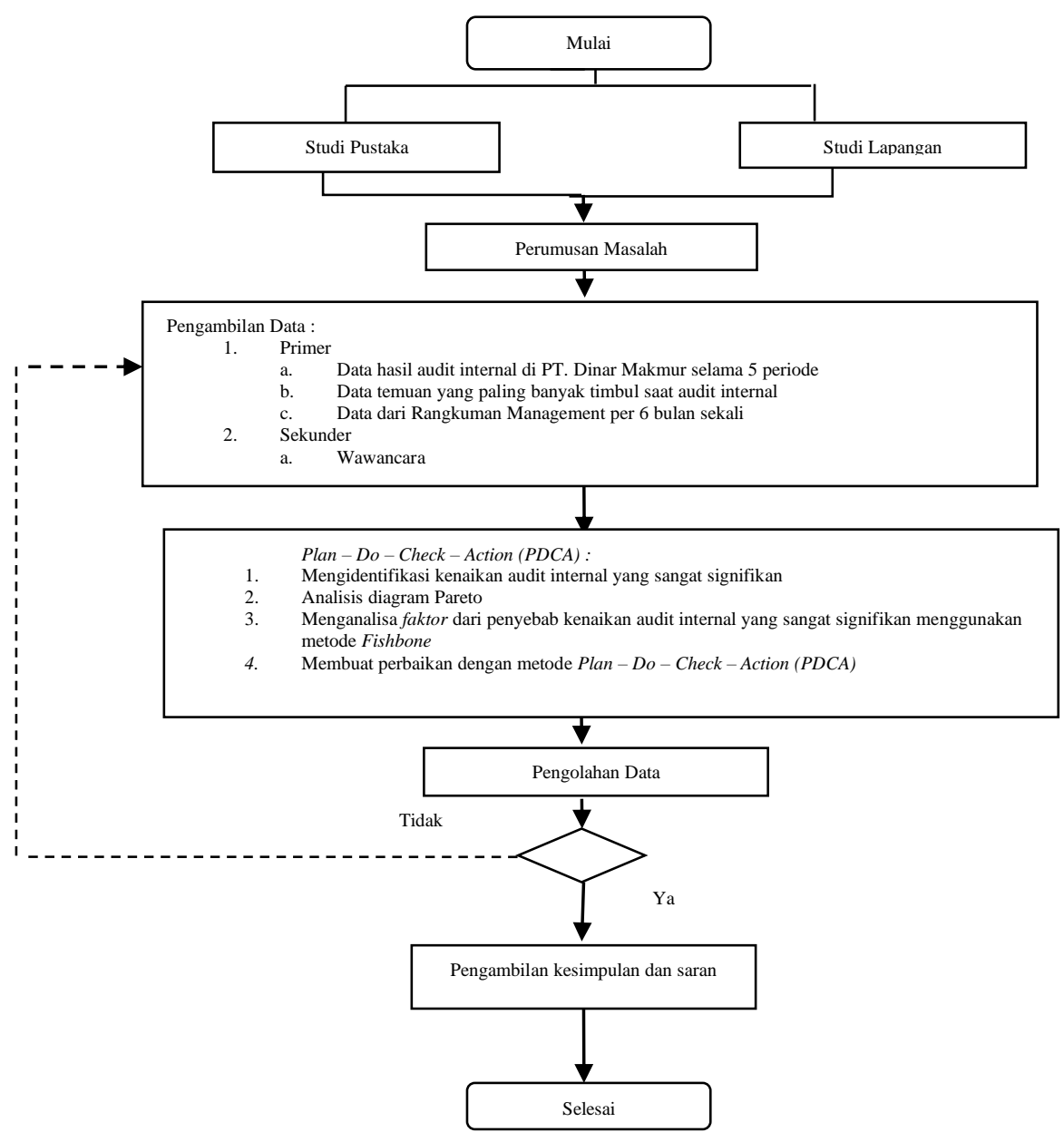

Gambar 3. Flow Penelitian

\section{HASIL DAN PEMBAHASAN}

Kenaikan temuan audit yang sangat signifikan dapat terlihat dari diagram pareto yang sudah dibuat, dengan berapa frekuensi terjadinya temuan audit dalam suatu masaalah, seperti contoh dibawah ini :

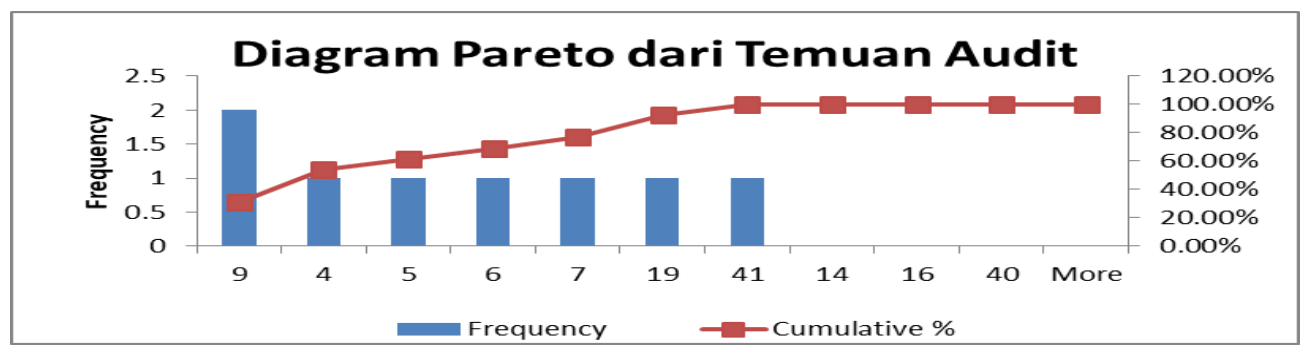

Gambar 4. Diagram pareto dari temuan audit berdasarkan temuan

Dari Diagram pareto diatas dijelaskan adanya beberapa point penyebab yang dihasilkan dari temuan audit berdasarkan jenis temuannya dan disandarkan dengan ke 2 kategori diatas yaitu klausul 7.5.2 Pembuatan dan updatenya yaitu termasuk pada point nomor $2,3,6,8,11,12,13$ dan klausul 7.5.3 pengendalian dokumen informasi yaitu termasuk pada point nomor $1,4,5,7,9,10$. Ditemukan temuan 
yang paling banyak muncul yaitu pada point "pengisin dokumen tidak lengkap" yang berjumlah 40 temuan selama 5 periode. Jadi, ditinjau selama 5 periode kebelakang bahwa sistem pengendalian dokumen dan berdasarkan "pengisian dokumen tidak lengkap" yang paling banyak temuan.

Analisis hipotesis yang dipakai yaitu untuk mengetahui perbaikan yang dilakukan apakah sudah efektif ataukah belum, dengan membandingkan dua data sebelum perbaikan dan sesudah perbaikan:

$$
\begin{gathered}
x \text { before }=\frac{\sqrt{\text { Total Temuan audit internal sebelum perbaikan }}}{\mathrm{n}} \\
x \text { after }=\frac{\sqrt{\text { Total Temuan audit internal sesudah perbaikan }}}{\mathrm{n}}
\end{gathered}
$$

Keterangan :

$\mathrm{x}$ before $\quad=$ Gap hasil temuan audit internal sebelum dilakukan perbaikan

$\mathrm{x}$ after $\quad=$ gap hasil temuan audit internal yang sudah dilakukan perbaikan

$\mathrm{n} \quad \quad=$ Jumlah frekuensi (Departemen)

Penghitungan Perbandingan Hasil Audit Internal Sebelum dilakukan perbaikan :

$$
\begin{gathered}
x \text { before }=\frac{\sqrt{\text { Total Temuan audit internal sebelum perbaikan }}}{\mathrm{n}} \\
x \text { before }=\frac{\sqrt{40}}{12} \\
x \text { before }=\frac{\sqrt{40}}{12} \\
x \text { before }=0,52 \text { sama dengan } 52 \%
\end{gathered}
$$

Penghitungan Perbandingan Hasil Audit Internal Setelah dilakukan perbaikan :

$$
\begin{gathered}
x \text { after }=\frac{\sqrt{\text { Total Temuan audit internal sesudah perbaikan }}}{x \text { after }=\frac{\sqrt{30}^{\mathrm{n}}}{\sqrt{30}}} \\
x \text { before }=\frac{{ }^{12}}{x \text { after }}=0,38 \text { sama dengan } 45 \%
\end{gathered}
$$

Dari hasil perhitungan yang sudah dilakukan diatas terlihat adanya penurunan dari hasil perbaikan yang sudah dilakukan sebanyak $7 \%$. Setelah diambil dari pokok masalah yang sudah ada maka dilakukan penelitian mengapa banyaknya temuan yang ada pada klausul 7.5 Pengendalian dokumen informasi dengan menggunakan diagram tulang ikan/fishbone analysis.

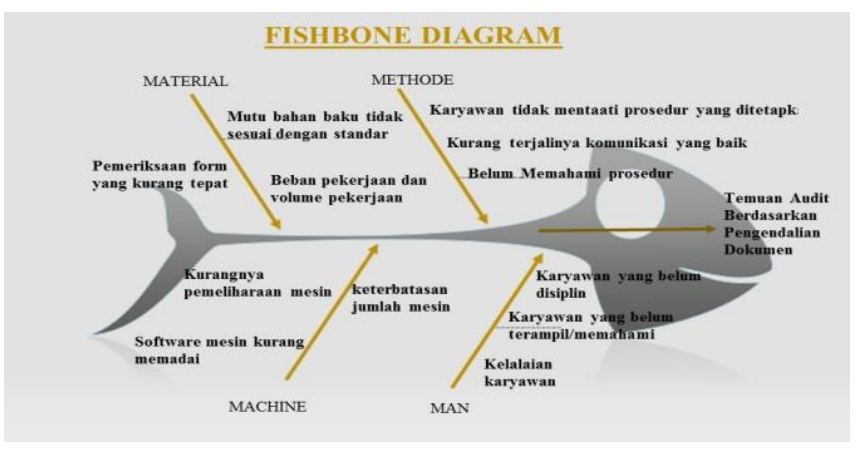

Gambar 5. Diagram tulang ikan/fishbone analysis pengendalian dokumen informasi 
Dari diagram diatas dinyatakan bahwa banyak beberapa faktor dari manusia yaitu karyawan yang belum disiplin terhadap pekerjaan, karyawan yang belum terampil/belum memahami standar iso yang belaku ataupun prosedur yang berlaku, kelalaian karyawan terhadap pekerjaannya dalam mengisi dokumen. Pada faktor mesin yaitu kurangnya pemeliharaan mesin yang membuat sistem tidak dapat berjalan sesuai rencana, keterbatasan jumlah mesin yang membuat karyawan banyaknya kesibukan, software mesin yang kurang memadai membuat pekerjaan tidak automatis. Pada faktor metode yaitu karyawan tidak mentaati prosedur yang sudah ditetapkan oleh perusahaan, Kurang terjalinnya komunikasi yang baik antar karyawan maupun atasan menjadikan tidak satu tujuan, belum memahami prosedur pekerjaannya sendiri. Pada faktor material yaitu mutu bahan baku tidak sesuai dengan standar yang sudah ditetapkan, pemeriksaan form yang kurang tepat ataupun tidak teliti, beban pekerjaan dan volume pekerjaan yang begitu banyak menyebabkan karyawan tidak fokus melakukan satu pekerjaan.

Kegagalan sistem management mutu (ISO 9001, 2015) terlihat dengan banyaknya hasil temuan audit yang muncul terutama pada klausul 7.5 Pengendalian dokumen informasi. Jadi, perbaikan yang akan diambil yaitu memberi pengetahuan dan inovasi kepada karyawan agar lebih bersemangat dan lebih memahamibidang pekerjaannya dan sistem managemen mutu ataupun standar yang sudah ditetapkan pada perusahaan dengan mengadakan training antar bagian. Proses awal yang akan dilakukan yaitu membuat jadwal training untuk semua bagian dan dievaluasi langsung setiap training sudah selesai.

Setelah dilakukannya test sesuai dengan schedule yang sudah ditetapkan, maka hasil dari training masing-masing bagian akan dievaluasi sebagai bukti apakah masih banyaknya karyawan yang belum memahami pengendalian dokumen informasi terhadap konsistensi pekerjaannya. Dari hasil evaluasi training yang sudah dilakukan disemua bagian pada training pengendalian dokumen informasi, dan mendapatkan hasil sebagai berikut :

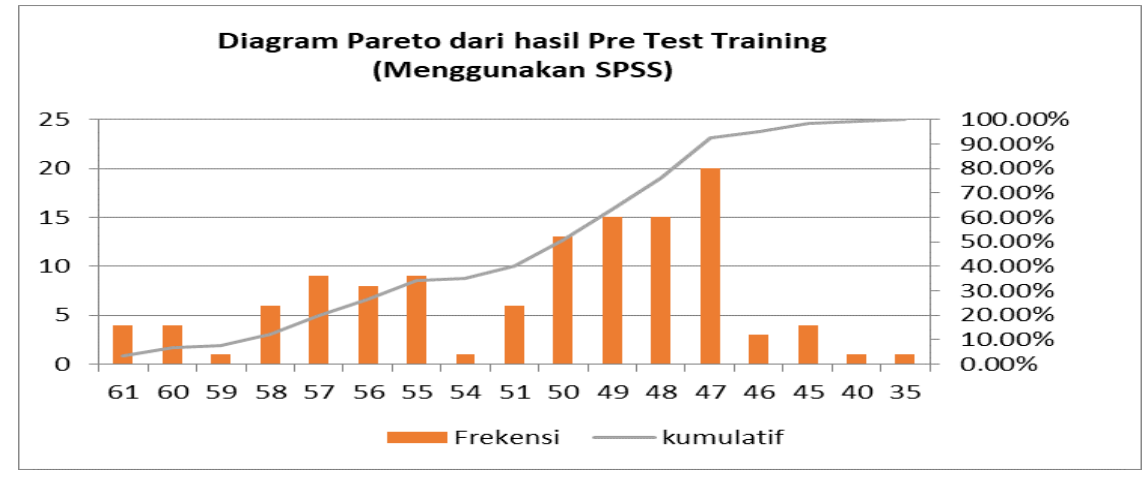

Gambar 6. Grafik nilai Pretest

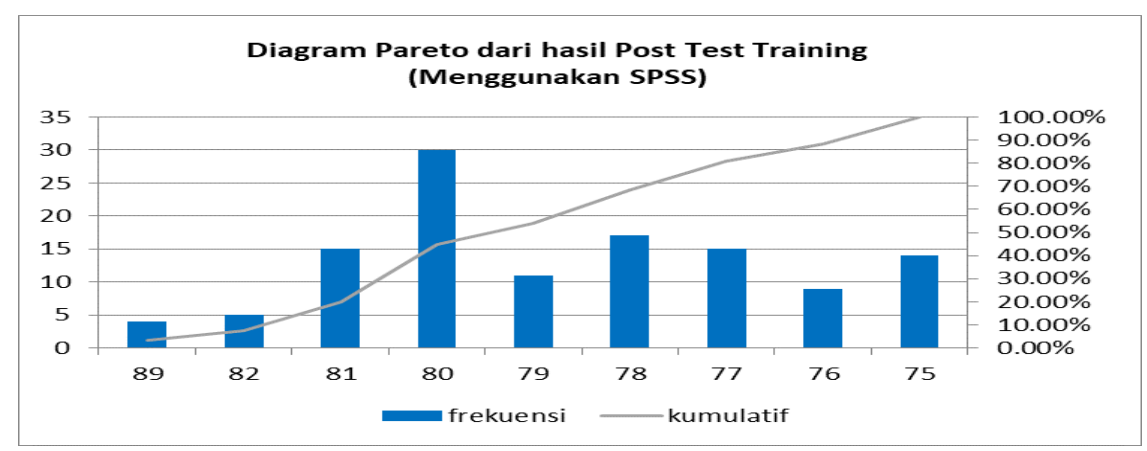

Gambar 7. Grafik nilai Posttest

Hasil perbaikan yang dilakukan dengan melaksanakan training untuk memberi pengetahuan tentang (ISO 9001, 2015) kepada karyawan sudah baik yaitu terlihat dari hasil analysis diagram pareto yang sudah dibuat, adanya peningkatan pengetahuan karyawan dari sebelum menerima materi training dengan mengisi soal dan sesudah mnerima materi training dan mengisi soal setelahnya. 
Masih ada beberapa karyawan yang belum sesuai dengan standar akan memahami pengendalian dokumen informasi terhadap pekerjaannya sendiri, maka bagi karyawan yang belum lulus pada training yang sudah dilakukan kemudian akan diberikan schedule untuk remedial menjawab soal dan di training untuk kedua kalinya. Berikut hasil yang sudah didapatkan oleh semua karyawan yang dinyatakan lulus terhadap training yang sudah diberikan, maka disebutkan karyawan sudah memahami akan materi yang sudah disampaikan dan ilmunya yang akan digunakan dilapangan/ditempat pekerjaannya. Selain perbaikan yang dilakukan dengan mengusulkan re-training setiap tahunnya, dan dibuatkan juga perbaikan untuk mengontrol semua dokumen yang ada di setiap bagian, dengan membuat jadwal pengontrolan dokumen setiap minggunya ke setiap-setiap bagian yang bertujuan untuk mengetahui setiap bagian sudah melakukan tugasnya dengan baik terutama mengisi checksheet dan lainnya.

Analisa untuk menilai Efektifitas (Achievement Rate) adalah sebagai berikut penghitungan secara efektifitas untuk perbaikan yang sudah dilakukan apakah sudah efektif atau tidak.

$$
\begin{aligned}
& \mathrm{AR}=\frac{\text { Total temuan klausul }}{\text { Jumlah bagian } \times \text { Jumlah point check }} \\
& \begin{aligned}
\mathrm{AR} & =\frac{40}{12} \times 26 \\
& =\frac{40}{312} \\
=0, & 12 \text { sama dengan } 12 \%
\end{aligned}
\end{aligned}
$$

Jadi, nilai efektifitas yang sudah dihitung dari total temuan audit yang sudah berjalan mencapai $12 \%$ tingkat keberhasilan yang sudah dilakukan.

Setelah dilakukannya perbaikan, PT. Dinar Makmur melaksanakan audit kembali pada periode Juli-Desember 2018 yang dilakukan pada awal Februari dimulai pada tanggal 4 - 8 Februari 2019 dan di evaluasi hasil audit internal pada tanggal 11 - 16 februari 2019 terlihat bahwa adanya penurunan hasil temuan audit internal yaitu klausul 7.5 pengendalian dokumen informasi terutama pada pengisian dokumen tidak lengkap.

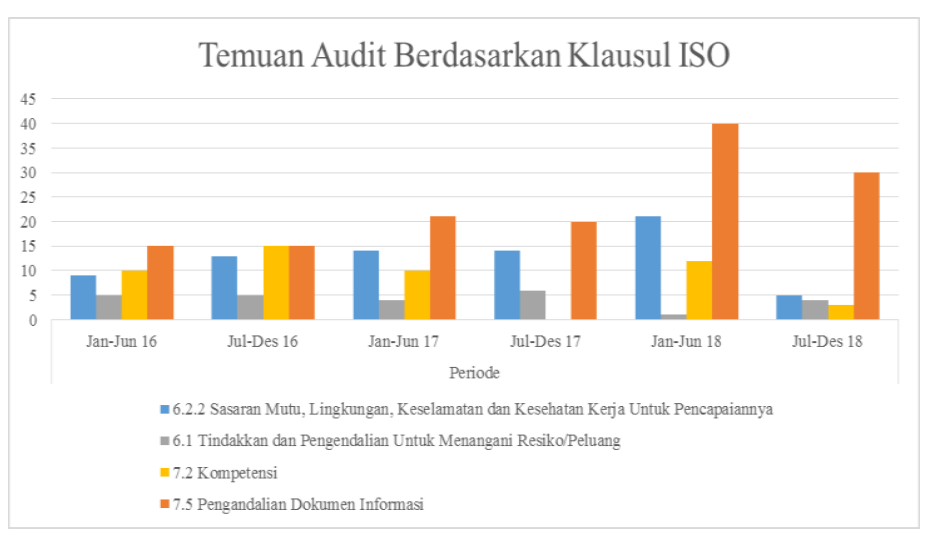

Gambar 8. Diagram temuan audit berdasarkan klausul ISO setelah perbaikan

Berdasarkan diagram diatas menunjukkan bahwa adanya penurunan hasil temuan audit internal pada periode juli - desember 2018 sebanyak 10 temuan. Dari sebelumnya temuan pada periode januari - juni 2018 sebanyak 40 temuan, dan periode berikutnya pada periode juli - desember 2018 sebanyak 30 temuan. Dan berdasarkan jenis temuannya juga dapat terlihat adanya penurunan untuk pengisian dokumen tidak lengkap sebagai berikut: 


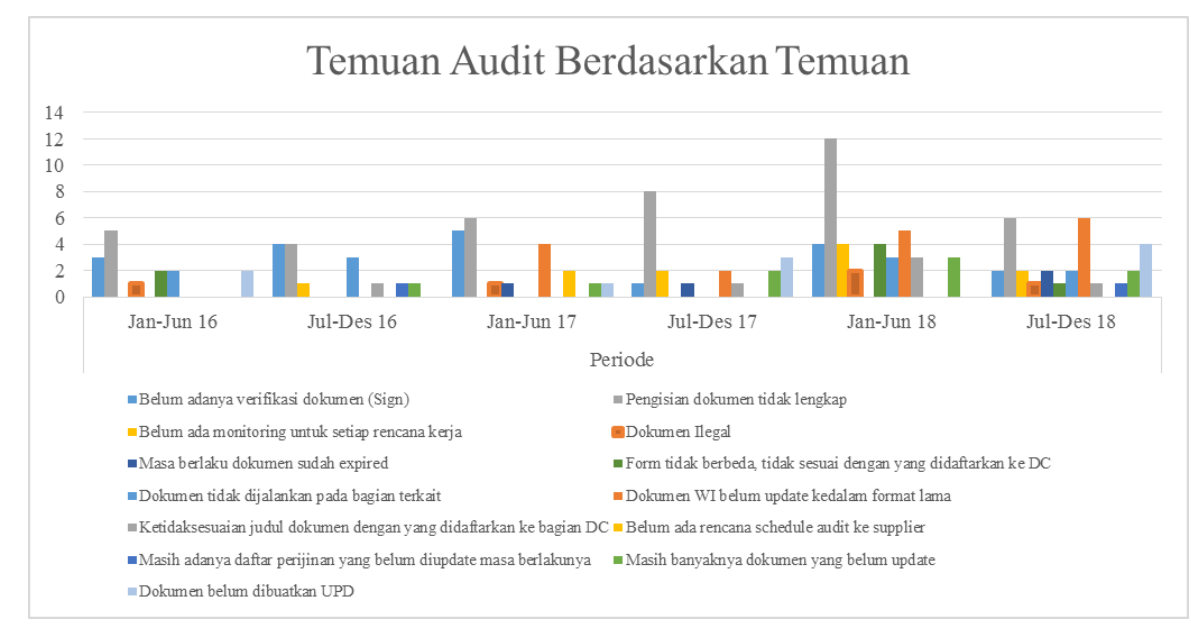

Gambar 9. Grafik temuan audit berdasarkan temuan

Tabel 4.9 Tabel Pareto dari temuan audit berdasarkan temuan

\section{KESIMPULAN}

Berdasarkan analisis yang telah dilakukan, ada beberapa kesimpulan sebagai berikut:

Berdasarkan temuan audit selama 5 periode terakhir, temuan yang paling banyak terdapat pada klausul 7.5 Pengendalian dokumen informasi. Titik utama berdasarkan kategori temuan yang paling banyak adalah "pengisian dokumen yang tidak lengkap" sebanyak 40 temuan diakhir periode yaitu januari-juni 2018. Analisis faktor-faktor penyebab dari penyebab banyaknya temuan yang dihasilkan berdasarkan 4M (Material, Machine, Methode, Man) terdapat dari beberapa faktor yang sudah dijelaskan, dan faktor yang paling banyak dapat terlihat dari manusianya sendiri bahwa masih banyaknya karyawan belum konsisten terhadap pekerjaannya terutama kepada checksheet/dokumen yang belum lengkap dalam pengisiannya, disebabkan karena banyaknya pekerjaan yang membuat pengisian checksheet/dokumen belum terisi dan tidak lengkap.

Perbaikan yang dilakukan dalam masalah ini adalah membuat PLAN (Perencanaan) yaitu schedule training pengendalian dokumen informasi, DO (Melaksanakan) menyebarluaskan schedule training pengendalian dokumen informasi kepada seluruh bagian untuk dilaksanakan training sesuai dengan jadwal yang sudah ditetapkan dan karyawan diberikan soal untuk menjawab pertanyaanpertanyaan yang sudah dibuat untuk melihat apakah karyawan sudah memahami atau mengerti atas materi yang sudah disampaikan, CHECK (Memeriksa) Mengevaluasi hasil training yang sudah diisi oleh semua yang karyawan yang telah mengikuti training pengendalian dokumen informasi, ACTION (Menindak) jadi didapatkan tindakan standarisasi untuk dilakukannya training pengendalian dokumen informasi setiap satu tahun sekali untuk mengingatkan karyawan terhadap kesadaran untuk mengisi checksheet/dokumen dan menurunkan temuan hasil audit 7.5 pengendalian dokumen informasi, ada juga tindakan perbaikan (Corrective action) yang dilakukan membuat schedule pengontrolan dokumen untuk semua bagian setiap minggunya sesuai jadwal yang ditetapkan.

Setelah penghitungan efektifitas dari perbaikan yang sudah dilakukan yaitu dengan mentraining karyawan untuk pengendalian dokumen informasi, maka akan dihitung efektifitas perbaikan dengan karyawan sudah mengerti atau memahami training tersebut. Total temuan klausul yang didapatkan setelah dilakukannya audit dan dibagi dari jumlah bagian dikalikan dengan jumlah point yang diaudit. Jadi hasil peningkatan dari nilai audit sebanyak $12 \%$ dari tingkat keberhasilan yang dilakukan. Setelah dilakukan perbaikan terlihat adanya penurunan di periode selanjutnya, pada periode Januari - juni 2018 sebanyak 40 temuan dan pada periode juli - desember 2018 sebanyak 30 temuan. Selisih penurunan yng sudah dicapai sebanyak 10 temuan. Analisis hipotesis yaitu untuk mengetahui hasil perbaikan yang dilakukan apakah sudah efektif atau belum dengan membandingkan dua data sebelum perbaikan dan sesudah perbaikan. Dari penghitungan $\mathrm{x}$ before sebelum dilakukan perbaikan sebanyak $52 \%$ dan penghitungan $\mathrm{x}$ after setelah dilakukannya perbaikan sebesar $45 \%$. Jadi dapat terlihat perbandingan keberhasilan audit dan penurunan dari hasil perbaikan yang sudah dilakukan sebanyak $7 \%$. 


\section{DAFTAR PUSTAKA}

ISO 9001. (2015) Quality Management System Requirement. International Organization, Switzerland. Kurniawan, Cepi dan Hery Hamdi Azwir. (2018). Penerapan Metode PDCA untuk Menurunkan Tingkat Kerusakan Mesin pada Proses Produksi Penyalutan. Journal of Industrial Engineering. Scientific Journal on Research and Application of Industrial System, Vol. 3, No.2, September 2018, hal 105-118: President University.

Silaban, Bernard E. \& Sugianto Yusup. (2011). Implementasi Sistem Manajemen Mutu ISO 9001: 2008 pada Industri Kontraktor (Studi Kasus PT. MAK). Jurnal: Esensi, 14 (3), hlm. 16-38 